Gut, 1987, 28, S1, 131-134

\title{
Postheparin plasma diamine oxidase increases in patients with coeliac disease during gluten free diet
}

\author{
L D'AGOSTINO, B DANIELE, S PIGNATA, M V BARONE, C CIACCI, \\ R SOLLAZZO, AND G MAZZACCA
}

From the Cattedra di Malattie dell'Apparato Digerente, 2a Facoltà di Medicina, 80131 Napoli, Italy.

SUMMARY An intravenous injection of heparin releases diamine oxidase (DAO) from villous tip enterocytes. In a previous study, we found that postheparin plasma DAO (PHD) values were significantly lower in patients with malabsorption syndrome and small bowel atrophy at jejunal biopsy than in normal subjects. In this study we performed the PHD test in 14 coeliac patients before and after three and six months of gluten free diet to show whether the enterocytes maturing processes induced by the diet joined with enhanced PHD values and to assess the clinical usefulness of this test. In all subjects jejunal biopsy carried out after six months showed a partial but consistent histological recovery. The clinical status, xylosuria and daily faecal fat excretion improved progressively and there was a significant increase $(p<0.001)$ in mean PHD activity that reached the normal range after three months. After six months a further slight increase of the mean PHD value was recorded. These data indicate that PHD values rise together with the improved intestinal absorptive functions of coeliac patients on gluten free diet and that this test is a useful tool in monitoring recovery of the small bowel mucosa.

Diamine oxidase (DAO) is an enzyme whose low plasma values are enhanced by an intravenous injection of heparin which releases the enzyme from the enterocytes of the villus tip. ${ }^{1}$ Diamine oxidase, which is not excreted in active form in urine and bile, is rapidly removed from plasma by liver uptake. ${ }^{2}$ Lower postheparin plasma DAO (PHD) values have been found in subjects with an overt malabsorption syndrome and histologically proven small bowel mucosa atrophy than in normal subjects, ${ }^{3}$ and a significant inverse correlation between PHD and faecal fat excretion was found. ${ }^{4}$

Coeliac disease, a clinical condition in which small bowel mucosa atrophy is reverted by gluten free diet, is an interesting human model of intestinal adaptation. ${ }^{5}$ The dramatic proliferative changes induced by gluten free diet determine a rapid reconstitution of the mature enterocytic mass; ${ }^{6}$ these mucosal modifications are only indirectly reflected by the currently available tests of intestinal function that assess the absorptive capability of the small bowel. The detection in plasma of enhanced concentrations of DAO which directly mirrors the morphologic and functional integrity of the small bowel mucosa ${ }^{347}$ could

Address for correspondence: Luciano D'Agostino, MD, Divisione di Gastroenterologia, 2a Facolta' di Medicina, via S Pansini 5, 80131 Napoli, Italy. be useful in monitoring mucosa recovery in coeliac patients on gluten free diet. To this end we performed the PHD test, xylosuria and faecal fat excretion (the two most widely used tests of malabsorption) in subjects with coeliac disease before and during treatment.

\section{Methods}

\section{PATIENTS}

Heparin (15000 IU) was injected into an antecubital arm vein by intravenous bolus in 14 subjects ( 10 women and four men; mean age $42 \pm 17$ years) with coeliac disease before and three and six months after starting gluten free diet. At the same time daily faecal fat excretion and xylosuria were carried out.

In all cases diagnosis was made by histological examination of jejunal mucosa samples obtained by Crosby capsule. A control biopsy was carried out after six months of gluten free diet. In each subject morphometric evaluation of small bowel mucosa was done with a LEITZ ocular micrometer.

The patients were referred to hospital because of clinical and laboratory signs of malabsorption syndrome; these progressively reverted after the starting of the gluten free diet. Laboratory signs of altered 
liver function were absent. Informed consent was obtained from all patients. No complications from the heparin bolus or jejunal biopsy occurred. In all subjects partial thromboplastin time was monitored and returned to normal values within five hours after heparin injection.

\section{DAO ASSAY}

Blood samples $(4 \mathrm{ml})$ withdrawn by vein catheter were collected in heparinised tubes at $0,5,15,30,45$, $60,90,120$ minutes after the iv heparin bolus. All samples were centrifuged at $3000 \mathrm{~g}$ and the plasma was stored at $-20^{\circ} \mathrm{C}$ and assayed for DAO within a week. Diamine oxidase assay was done by the Okuyama and Kobayashi method ${ }^{8}$ as modified in our previous study. ${ }^{9}$ Diamine oxidase activity was expressed as $\mathrm{U} / \mathrm{ml}(1 \mathrm{U}=1 \mathrm{nM}$ of putrescine dihydrochloride oxidated in one hour at $37^{\circ} \mathrm{C}, \mathrm{pH} 7 \cdot 2$ ). The area under the DAO release curves, expressed as $\mathrm{U} / \mathrm{ml} \cdot \mathrm{min}$, was calculated by trapezoid method.

\section{FAECAL FAT EXCRETION}

Patients received a standard hospital diet containing $100 \mathrm{~g}$ fat daily during the three days of faeces sampling. A faecal fat excretion, assayed according to Van der Kamer, ${ }^{10}$ of less than $7 \mathrm{~g} /$ day was taken as normal.

\section{D-XYLOSE ABSORPTION TEST}

D-xylose $(25 \mathrm{~g})$ in $250 \mathrm{ml}$ of water was administered to patients the morning after an overnight fast. Urine was collected for five hours. An excretion of $4 \mathrm{~g}$ or more was considered normal. The assay was carried out according to a modified method ${ }^{11}$ of Roe and Rice. ${ }^{12}$

\section{STATISTICAL METHODS}

Statistical evaluation includes a two-tailed unpaired Student's $t$ test. Results, expressed as mean \pm SD, were considered significant when $\mathrm{p}<0.05$.

\section{Results}

Postheparin plasma values in 14 patients with coeliac disease before and after three and six months of gluten free diet are shown in Figure 1. Increased mean PHD values, reaching the normal range, were present after three months; after six months a further slight increase of these values was recorded. Mean \pm SD PHD area values (Fig. 2) were $195 \pm 94$ on diagnosis and $411 \pm 119$ and $493 \pm 110(\mathrm{p}<0.001$; normal values more than 370 ) after three and six months of treatment respectively.

The test was also undertaken in five patients after only 10 days of diet; a significant increase in PHD values was recorded in three of these. Daily faecal fat

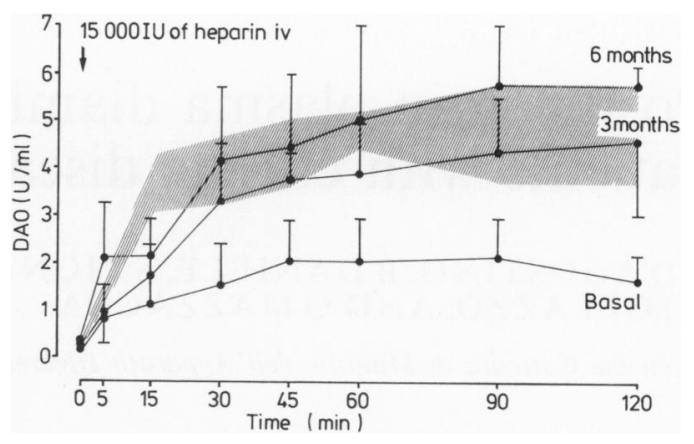

Fig. 1 Postheparin DAO release curves in 14 subjects with coeliac disease before and during gluten free diet.

Shaded area represents the normal range.

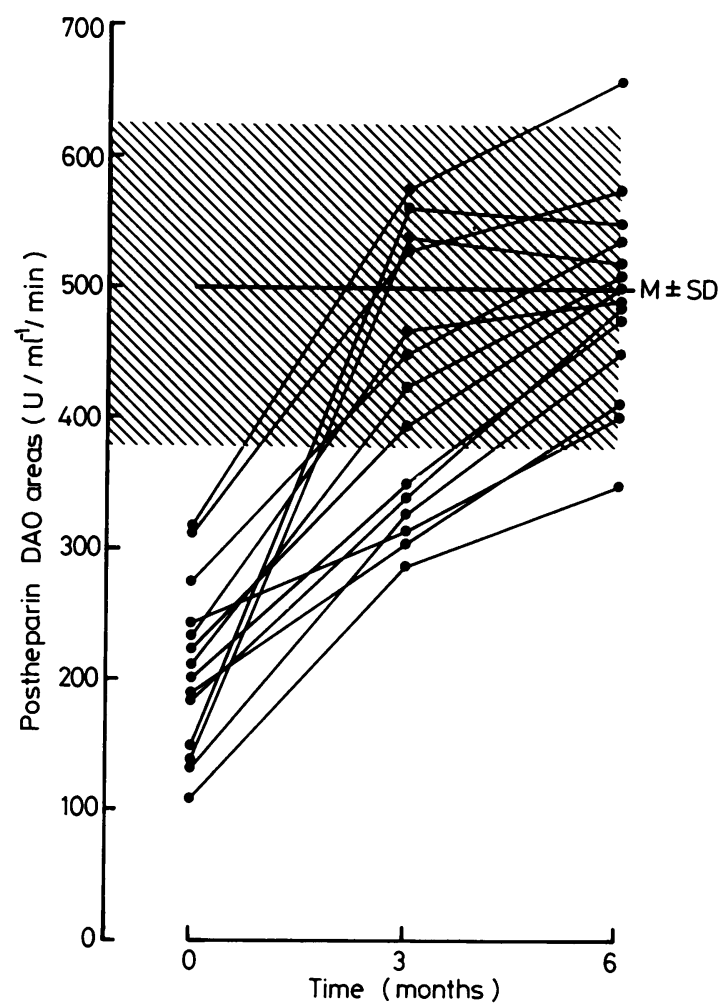

Fig. 2 Postheparin DAO area values in 14 subjects with coeliac disease before and during gluten free diet. Shaded area represents the normal range.

excretion, xylosuria and morphometric data are shown in the Table.

Daily faecal fat excretion progressively decreased and xylosuria increased during treatment. The histological evaluation of jejunal specimens after six 
Table Changes in daily faecal fat excretion, xylosuria, villus height and crypt height in 14 subjects before and during gluten free diet.

\begin{tabular}{|l|c|c|c|}
\hline \multicolumn{1}{|c|}{ Months } & 0 & 3 & 6 \\
\hline Faecal fat excretion (g/day) & $27 \pm 9$ & $13 \pm 5$ & $9 \pm 2$ \\
\hline D-xylose excretion $(g)$ & $2 \cdot 7 \pm 1$ & $3 \cdot 8 \pm 2 \cdot 1$ & $4 \cdot 2 \pm 1 \cdot 8$ \\
\hline Villus height $(\mu \mathrm{m})$ & $35 \pm 3$ & & $255 \pm 105$ \\
\hline Crypt height $(\mu \mathrm{m})$ & $328 \pm 28$ & & $167 \pm 63$ \\
\hline
\end{tabular}

months of diet showed an incomplete normalisation of villus morphology in all patients.

\section{Discussion}

This study shows that in patients with coeliac disease on gluten free diet the functional recovery of small bowel mucosa closely accompanies the rapid normalisation of the PHD test. Diamine oxidase is an enzyme located in villus tip enterocytes of mammalians ${ }^{1}$ and its activity increases successively from the duodenum to the ileum. ${ }^{913}$ This enzyme functions as a plasma marker of small bowel mucosa maturation and integrity ${ }^{14}$ and injury and recovery in the rat. ${ }^{15}$ Heparin induces high DAO concentrations in plasma by releasing the enzyme from differentiated and non-replicating enterocytes. ${ }^{1}$ Patients with small bowel mucosa atrophy and malabsorption syndrome presented PHD values significantly lower than did normal subjects. Postheparin area values in these patients were also inversely correlated with the daily faecal fat excretion, indicating that PHD test explores the remaining mature enterocytic mass. ${ }^{4}$

These data induced us to investigate whether enterocyte maturing processes determined by gluten free diet were connected with increased amounts of releasable intestinal DAO in coeliac patients and to assess the usefulness of this test in monitoring small bowel mucosa recovery.

The results show that three months after starting treatment mean PHD values reached the normal range and that normal values were recorded at the six month evaluation. It is also interesting that the early clinical improvement induced by a few days of gluten free diet was associated with a significant increase in PHD values in three subjects. The absorption tests performed after three and six months showed a progressive improvement, and at six months quite complete normalisation of small intestinal absorptive functions, although the histological picture of jejunal specimens only partially improved. These findings are consistent with the observation that in coeliac patients on gluten free diet the mucosa of the distal small intestine improves more rapidly than that of the severely involved proximal bowel ${ }^{6}$ and with the prevalently distal location of DAO along the small bowel. ${ }^{9,13}$

The early increase in release of enterocitic DAO may depend upon the rapid maturing processes induced by gluten free diet. In fact, the diet induces the 'flat' coeliac mucosa, that shows a three-fold increase in the size of the proliferation compartment compared with normal and a net six-fold increase in crypt cell production rate, ${ }^{5}$ to shift to a normal replicative pattern with a progressive increase in the number of the mature enterocytes.

In conclusion, these data suggest that in patients with coeliac disease the functional recovery of the small bowel mucosa, revealed by clinical improvement and near-normalisation of absorptive tests is closely associated with high PHD values. Furthermore, the maturing processes that begin within a few days of gluten free diet, are clearly shown by increased PHD values. For the above reasons this test, carried out in man for the first time by us, ${ }^{3}$ appears to be a useful tool in the early monitoring of small bowel mucosa recovery.

The authors thank Drs F Sabbatini and A D'Arienzo for encouragement and Mr P Esposito for technical assistance. This work was supported in part by a grant from Ministero Pubblica Istruzione. Presented in part at the Poster session of the Italian Society of Gastroenterology (SIGE) meeting, Milan, November 14-16, 1985 and published in abstract form in Ital J Gastroenterol 1986; 18: 61 .

\section{References}

1 Shakir KMM, Margolis S, Baylin SB. Localization of histaminase (Diamine oxidase) in rat small bowel intestinal mucosa: site of release by heparin. Biochem Pharmacol 1977; 26: 2343-7.

2 D'Agostino L, Ciacci C, Capuano G, et al. Metabolic fate of plasma Diamine oxidase: evidence of isolated and perfused rat liver uptake. Digestion $1986 ; 34$ : 243-50.

3 D'Agostino L, Ciacci C, Daniele B, Barone MV, Sollazzo R, Mazzacca G. Plasma Diamine oxidase (DAO) and heparin. [Letter]. Dig Dis Sci 1984; 29: 1070-1.

4 D'Agostino L, Ciacci C, Daniele B, Barone MV, Sollazzo R, Mazzacca G. Postheparin plasma Diamine oxidase in subjects with small bowel mucosa atrophy. Dig Dis Sci 1987; 32: 313-17.

5 Watson AJ, Appleton DR, Wright NA. Adaptive cellproliferative changes in the small intestinal mucosa in coeliac disease. In: Polak JM, Bloom SR, Wright NA, Daly MJ, eds. Structure of the gut. Ware, Herts: Glaxo Group Research Ltd, 1982: 431-43. 
6 MacDonald WC, Brandborg LL, Flick AL, Trier JS, Rubin CE. Studies of celiac sprue. IV. The response of the whole length of the small bowel to a gluten-free diet. Gastroenterology 1964; 47: 573.

7 Luk GD, Bayless TM, Baylin SB. Plasma postheparin Diamine oxidase. Sensitive provocative test for quantitating length of acute intestinal mucosal injury in the rat. $J$ Clin Invest 1983; 71 : 1308-15.

8 Okuyama T, Kobayashi Y. Determination of Diamine oxidase activity by liquid scintillation counting. Arch Biochem Biophys 1961; 95: 242-50.

9 D'Agostino L, D'Argenio G, Ciacci C, Daniele B, Macchia V, Mazzacca G. Diamine oxidase in rat small bowel: distribution in different segments and cellular location. Enzyme 1984; 31 : 217-20.

10 Van der Kamer JH, Huinink HTB, Weijers HA. Rapid method for the determination of fat in feces. $J$ Biol Chem 1949; 177 : 347-52.
11 Goodhart JM, Kinsington GR. Modifications of the method for the estimation of xylose in urine. $J$ Clin Pathol 1968; 22 : 621-4.

12 Roe JH, Rice EW. A photometric method for the determination of free pentoses in animal tissues. $J$ Biol Chem 1948; 173: 507-12.

13 Biegański T. Biochemical, physiological and pathophysiological aspects of intestinal Diamine oxidase. Acta Physiol Pol 1983; 34: 139-53.

14 Luk GD, Bayless TM, Baylin SB. Diamine oxidase (DAO) a circulating marker for rat mucosal maturation and integrity. $J$ Clin Invest 1980; 66: 66-70.

15 Luk GD, Vaughan WP, Burke PJ, Baylin SB. Diamine oxidase as a plasma marker of rat intestinal mucosa injury and regeneration after administration of 1-B-DArabinofuranosylcytosine. Cancer Res 1981; 41: 2234 7. 